\title{
PERSISTENCE OF RIGHT VENTRICULAR HYPERTROPHY FOLLOWING MITRAL VALVOTOMY
}

\author{
BY \\ R. V. R. RODRIGUEZ TORRES,* J. MACKINNON, E. G. WADE, AND \\ C. F. H. VICKERS \\ From the University Department of Cardiology, Manchester Royal Infirmary \\ Received October 12, 1958
}

Severe pulmonary hypertension due to an increased hindrance to blood flow in the small pulmonary arteries frequently complicates mitral stenosis, and when this occurs electrocardiographic evidence of right ventricular hypertrophy $(\mathrm{RVH})$ is invariably present. Mitral valvotomy is commonly undertaken in patients with such changes, though their reversibility is the subject of controversy and opinions differ as to the benefit to be obtained from operation. In view of these conflicting opinions we have reviewed the results of surgical treatment of sixty patients with mitral stenosis and cardiographic evidence of $\mathrm{RVH}$, and find that in addition to excellent functional improvement in the majority, the electrocardiogram has returned to normal in almost 60 per cent of the survivors.

\section{Methods}

Mitral valvotomy was performed in approximately 200 patients in the Manchester Royal Infirmary by Mr. Frank Nicholson between 1952 and 1957 and of these 54 had electrocardiographic evidence of RVH. A further 6 such patients were operated on in the Manchester Regional Thoracic Surgical Centre by Mr. Gordon Jack and Mr. John Dark. Eleven (18\%) of these 60 patients died within 24 hours of operation. The 49 survivors (14 men, 35 women) have been closely followed and the cardiographic changes related to functional improvement and the valve size estimated by the surgeon at operation. All patients were examined clinically and radiologically in the University Department of Cardiology, Manchester Royal Infirmary, before operation and were considered to have predominant mitral stenosis with associated pulmonary hypertension. Two had mild aortic regurgitation in addition and one tricuspid regurgitation. Patients were classified functionally, using the New York Heart Association's classification (1939) and all have been reviewed recently. Those operated on within the last six months were not included.

Electrocardiograms were recorded before operation and at intervals after in all patients. The examination consisted of standard leads, augmented unipolar limb leads, and præcordial leads V1 to V6 using Wilson's central terminal. In two patients the standard leads only were recorded before operation.

\section{Criteria for the Electrocardiographic Diagnosis of Right Ventricular Hypertrophy}

The criteria used for the diagnosis of RVH in this paper are those suggested by Milnor (1957) and are as follows, using the definitions given here.

The duration of the QRS complex must be less than 0.12 second with in addition either (1) a mean frontal plane axis from $+110^{\circ}$ to $\pm 180^{\circ}$, or $-91^{\circ}$ to $\pm 180^{\circ}$, and/or (2) $R / S$ or $R^{\prime} / S$ ratio in lead V1 greater than 1.0 , with $R$ or $R^{\prime}$ greater than 0.5 millivolt (subsequently referred to as RVH pattern in V1).

(1) $R / S$ ratio. The ratio of the amplitude of the tallest single positive deflection in a lead (numerator) to that of the deepest negative deflection in the same lead (denominator). Amplitudes are measured from the $\mathrm{P}-\mathrm{Q}$ segment.

(2) $R^{\prime}$. The second of two positive components of a QRS complex that are separated by a downward deflection that reaches or crosses the iso-electric line. 
(3) Mean QRS axis. Mean manifest frontal plane QRS axis calculated from the nomogram of Carter et al. (1919).

(4) Frontal plane $Q R S$ axis. Normal $=0^{\circ}$ to $+110^{\circ}$; left axis deviation $=0^{\circ}$ to $-89^{\circ}$; right axis deviation $(\mathrm{RAD})=+110^{\circ}$ through $180^{\circ}$ to $-90^{\circ}$ (inclusive).

(5) QRS duration. Durations equal to or greater than $0.12 \mathrm{sec}$. are termed abnormal.

Whatever criteria are used to diagnose RVH by the electrocardiogram a small number of errors will be made. The most widely used criteria are those of Myers et al. (1948) and Sokolow and Lyon (1949). These are sometimes difficult to apply in practice, and do not provide for the diagnosis of RVH in the presence of an $R^{\prime}$ wave in V1. Milnor (1957) has shown by electrocardiographic and vectorcardiographic studies of normal persons and patients with heart disease that the most important and characteristic electrical change produced by RVH is the shift of the spatial QRS axis rightward and anteriorly, and because of this he criticizes Myers et al. (1948) and Sokolow and Lyon (1949) for not accepting right axis deviation (RAD) as evidence of RVH. He concludes that less than 0.15 per cent of the normal adult population have a mean frontal plane QRS axis more positive than $+110^{\circ}$ and gives good evidence why RAD greater than $+110^{\circ}$ indicates $\mathrm{RVH}$ and should be included in the criteria for its diagnosis.

Previous criteria have not provided for the diagnosis of $R V H$ when an $R^{\prime}$ wave appears in $V 1$ for it has been regarded as evidence of a conduction delay, which made it impossible to identify RVH. Milnor (1957) concludes that a tall $R$ wave or $R^{\prime}$ in V1 is the result of vectors of increased magnitude from a hypertrophied right ventricle and includes its presence in his criteria. The advantages of Milnor's (1957) over previous criteria are, therefore, the elimination of unnecessary factors, making practical application easier without any loss of diagnostic accuracy and their applicability to records with $R^{\prime}$ in V1.

A small proportion of patients with these criteria will have coronary artery disease and no $\mathrm{RVH}$, but this is also true of other criteria and is unlikely to lead to errors in the present investigation. We believe that occasionally the cardiogram although normal by Milnor's (1957) criteria may show minor changes due to RVH. No cases with electrocardiograms of this type before operation have been included and those showing such changes after operation are discussed later. Examples of cardiograms showing Milnor's (1957) criteria of RVH are shown in Fig. 1.
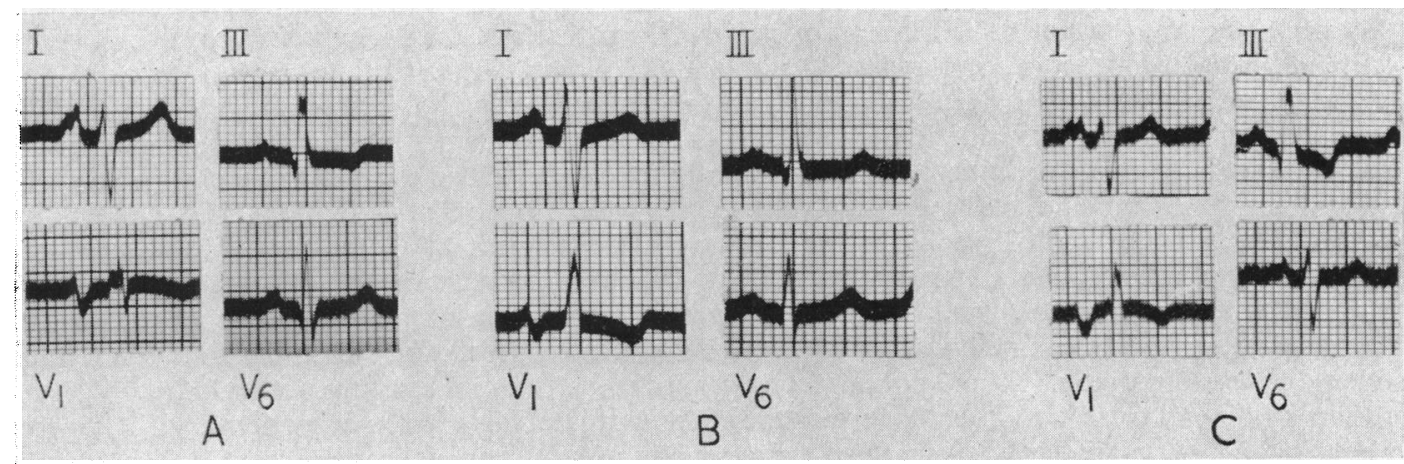

FIG. 1.-Criteria for diagnosis of right ventricular hypertrophy. (A) Abnormal right axis deviation with normal V1. (B) Normal axis deviation but with RVH pattern in V1. (C) Abnormal right axis deviation and $\mathrm{RVH}$ pattern in V1.

\section{RESULTS}

Table I shows the details of the cardiograms in the 49 surviving patients before and after operation. Before, all showed RVH for the following reasons: 19 had abnormal RAD plus RVH pattern in V1, 24 had normal axis but RVH pattern in V1, 4 had abnormal RAD with a normal V1, and 2 in whom only the standard leads were recorded showed abnormal RAD (one of these had an RVH pattern in V1 post-operatively).

Following mitral valvotomy the cardiogram returned to normal in $29(59 \%)$ of the survivors (Group 1) and an example is shown in Fig. 2. Although normal by Milnor's (1957) criteria we consider that 4 of these still show traces of RVH though very much less than before operation (Fig. 6). In the remaining 20 survivors (41\%) (Group 2) signs of RVH persisted though in 6 $(12.5 \%)$ considerable improvement occurred (Fig. 3$)$. Twenty-six $(65 \%)$ out of 40 patients having 
TABLE I

Details of the Electrocardiograms before and after Operation

\begin{tabular}{|c|c|c|}
\hline \multirow{2}{*}{ Electrocardiographic changes } & \multicolumn{2}{|c|}{ Number of cases } \\
\hline & $\begin{array}{c}\text { Before } \\
\text { operation }\end{array}$ & $\begin{array}{c}\text { After } \\
\text { operation }\end{array}$ \\
\hline 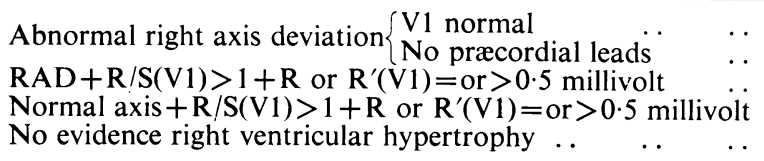 & $\begin{array}{r}4 \\
2 \\
19 \\
24 \\
-\end{array}$ & $\begin{array}{r}\frac{2}{3} \\
15 \\
29\end{array}$ \\
\hline
\end{tabular}

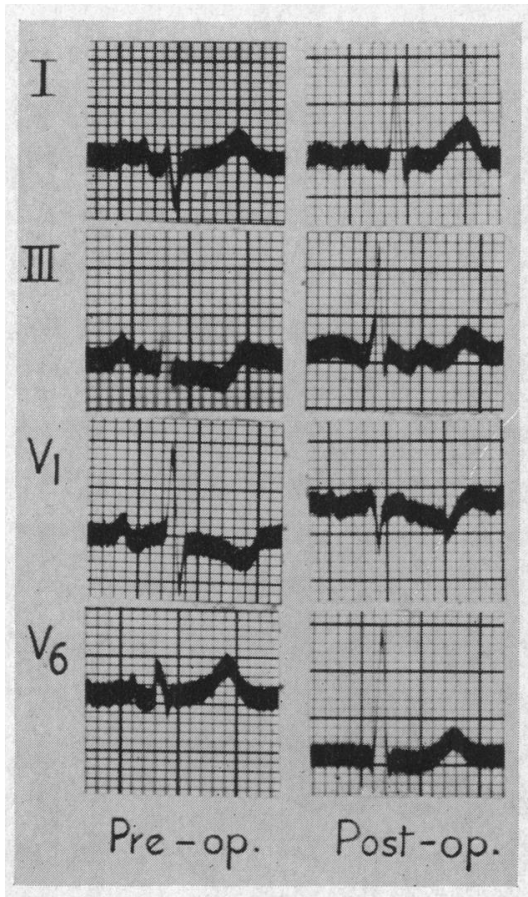

FiG. 2.- Return of electrocardiogram to normal within three months of operation. (Auricular fibrillation followed operation.)

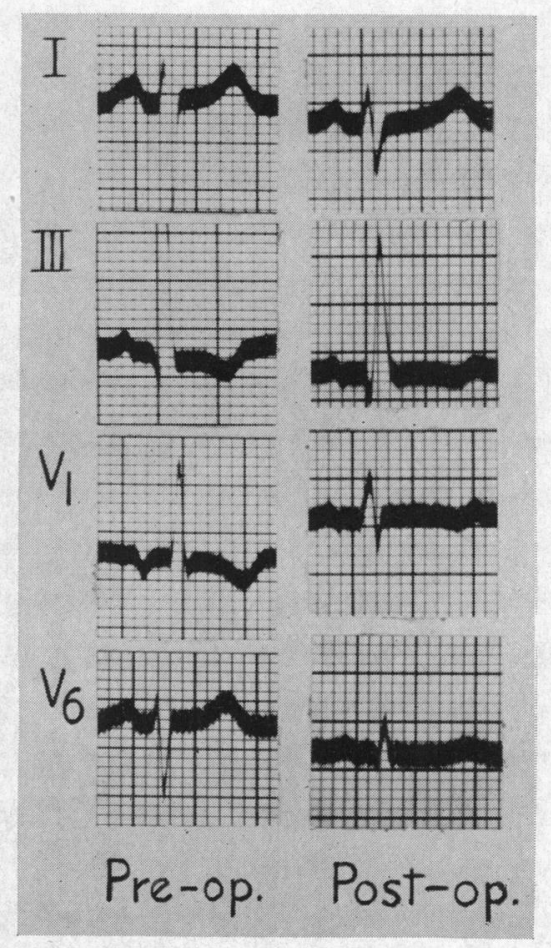

FIG. 3.-Improvement in the pattern of RVH six months after valvotomy.

a technically satisfactory operation (valve size estimated by the surgeon as greater than $3 \mathrm{~cm}$.) lost cardiographic evidence of RVH (Fig. 4). In the remaining $14 \mathrm{RVH}$ persisted though the severity decreased in 6 of them.

The time required for cardiographic reversion to normal ranged from less than three months to two years. Accurate assessment of the time taken after operation for the cardiogram to become normal was possible in 16 patients. Twelve became normal within 7 months (Fig. 2) and one within 8 months of operation; one still abnormal 7 months after operation was normal within 15 months; one showed continued improvement for 12 months before becoming normal (Fig. 5) and another for 24 months (Fig. 6). Only traces of $\mathrm{RVH}$ remain in four of the six records showing improvement (Fig. 3). In two of these the follow-up period is still only six months and they may 


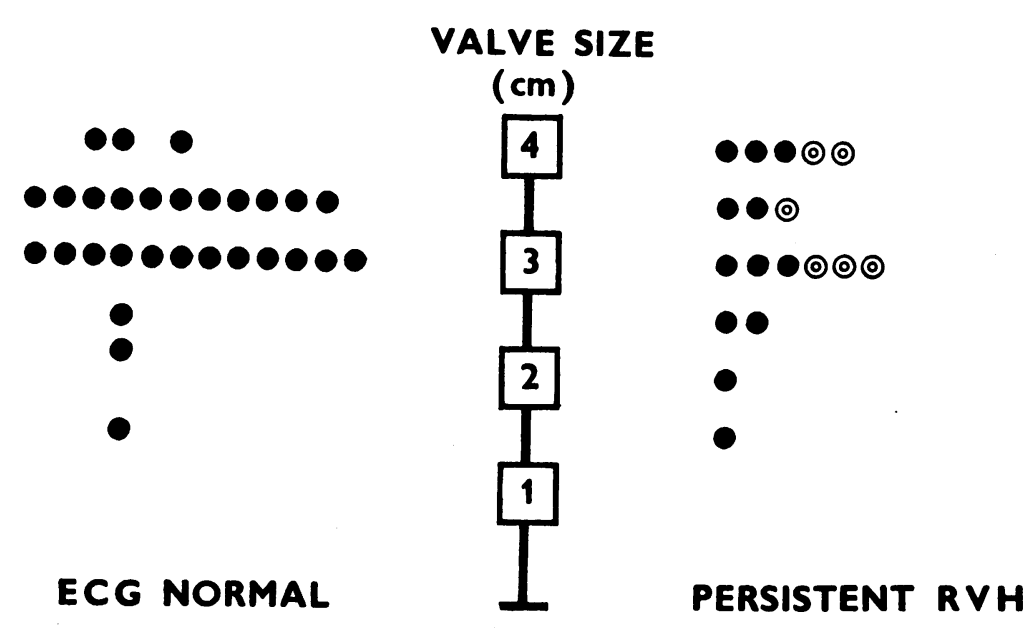

๑ Improved but not normal

FIG. 4.-Relationship between final valve size (surgeon's estimate) and postoperative change in electrocardiogram.

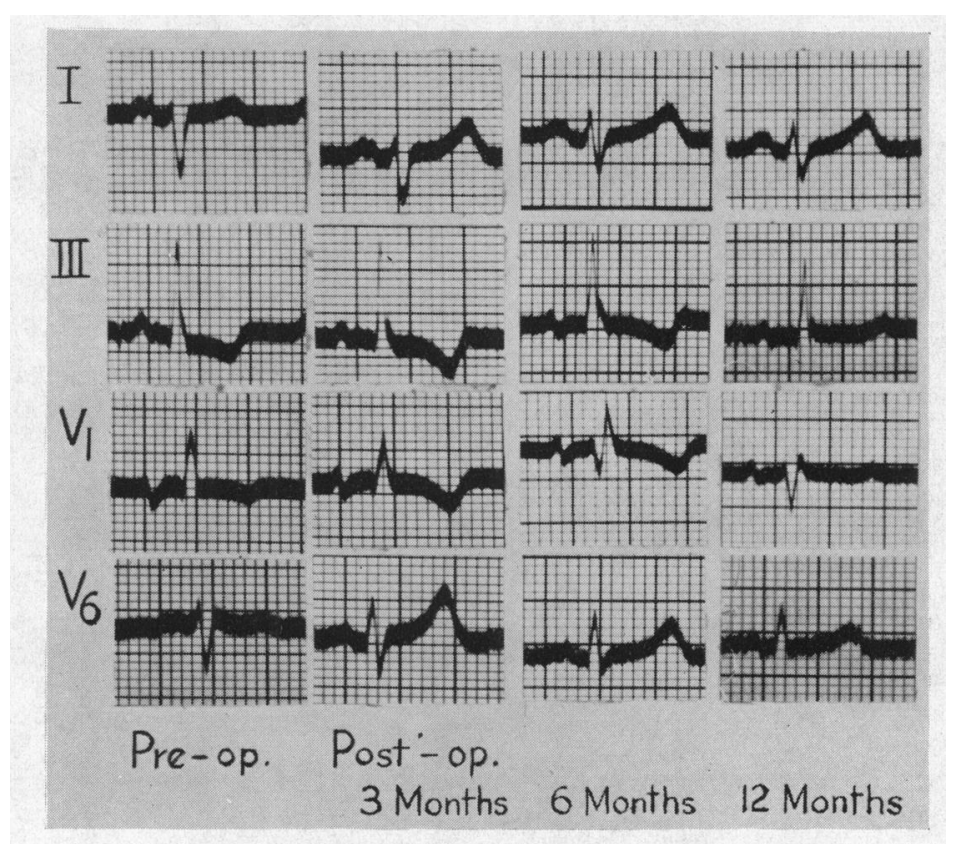

FIG. 5.-Reversion of the electrocardiogram occurring between six and twelve months after operation.

yet become completely normal. In one patient initial regression of the RVH pattern (but not to normal) was associated with functional improvement (Grade 4 to Grade 2) and disappearance of congestive heart failure. Two years later, however, congestive heart failure recurred and was associated with an increase in the severity of the RVH pattern which became similar to the original record. 


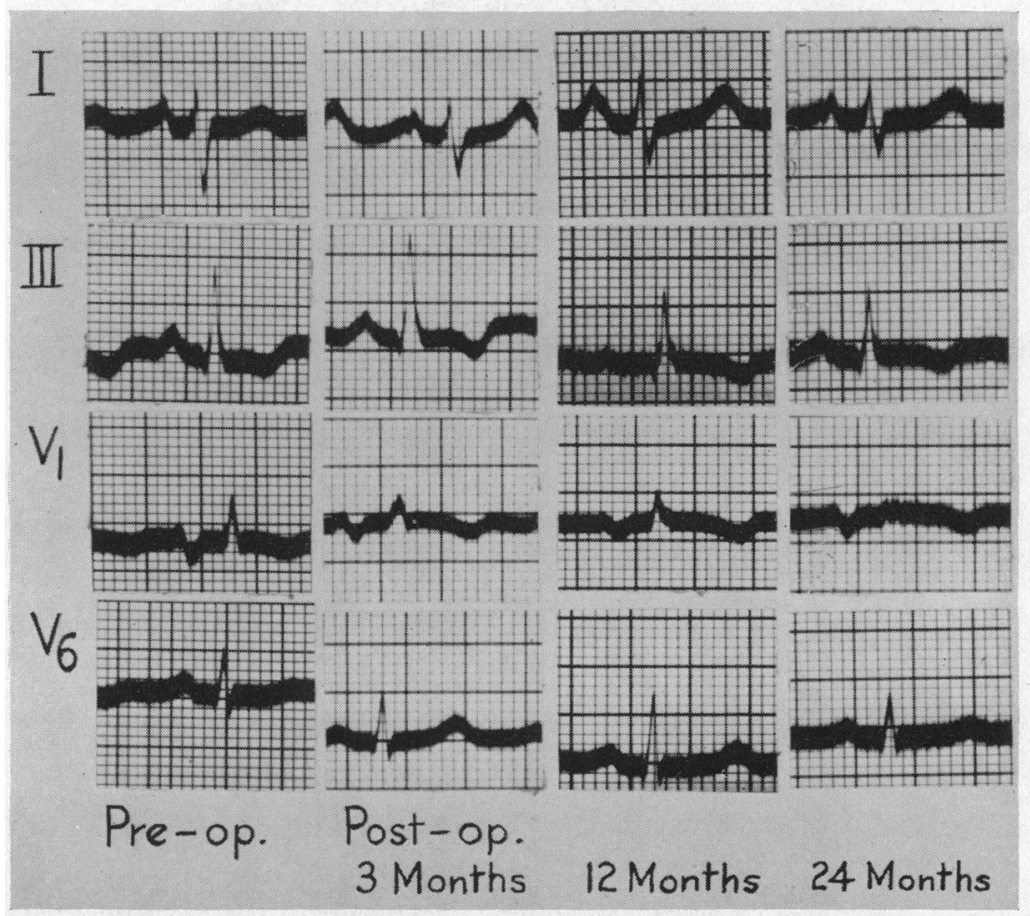

FIG. 6.-Slow improvement in the electrocardiogram over two years. The final record does not show RVH by Milnor's criteria although traces of it remain.

Two patients were operated on twice. The first showed temporary functional improvement following the initial valvotomy but no change in the electrocardiogram. Deterioration occurred after 18 months and at cardiac catheterization a high pulmonary capillary venous (PCV) pressure $(30 \mathrm{~mm} . \mathrm{Hg})$ was found. It was thought either that re-stenosis of the mitral valve had occurred or that the operation had not been satisfactory. Re-exploration revealed tight mitral stenosis and a good split was obtained: the cardiogram subsequently became normal. The second patient had two operations without achieving a satisfactory split of the valve and the cardiogram remained unchanged. One other patient in whom the cardiogram was unchanged following operation is thought to have had a re-stenosis of the valve because of recurring pulmonary congestion and a high PCV pressure $(31 \mathrm{~mm} . \mathrm{Hg})$.

Eight patients $(16 \%)$ developed persistent auricular fibrillation after operation. In the remainder the amplitude of the $P$ waves occasionally diminished-in one case from 6 to $2 \mathrm{~mm}$.

The age (29.5 and 29.9 years) and sex distribution of groups 1 and 2 was almost identical, but the cardiogram became normal in a higher proportion $(19$ of $27=70 \%$ ) of patients with symptoms of less than 7 years duration than in those with symptoms for longer than 7 years before operation (9 of $20=45 \%$ ) (Fig. 7). Approximately the same proportion of good splits was obtained at operation in both these groups.

Mortality rate in patients operated on between 1952-1954 (17\%) and between $1955-1957(19 \%)$ was similar though in the survivors the cardiogram returned to normal in a rather higher proportion of patients operated on in the first three years $(74 \%)$ compared with those operated on between 1955 and $1957(50 \%)$.

Pre-operatively, 44 of the surviving patients were placed in functional grades 3 or 4 and only 5 in grades 1 and 2. After operation 45 patients were classified as grade 1 or 2 and only 4 as grade 3 or 4 (Fig. 8). Only one was functionally worse after operation, two were unchanged, and two have deteriorated to their original grade following initial improvement (thought to be due to re-stenosis 


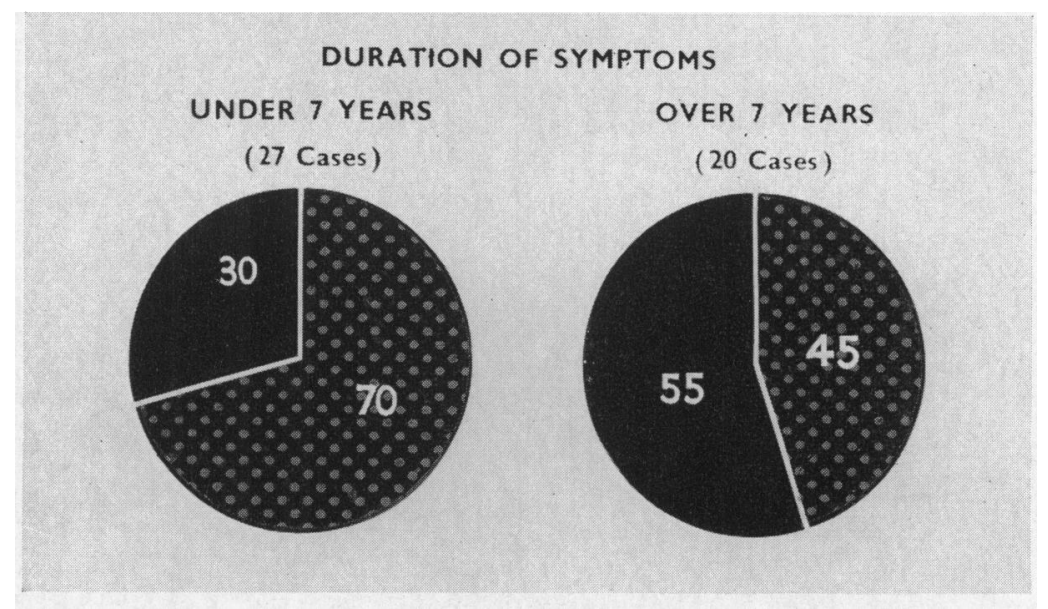

FIG. 7.-Relationship between duration of symptoms before valvotomy and electrocardiographic reversion. Stippled area=percentage of electrocardiograms returning to normal. Dark area=percentage of electrocardiograms showing persistent RVH.
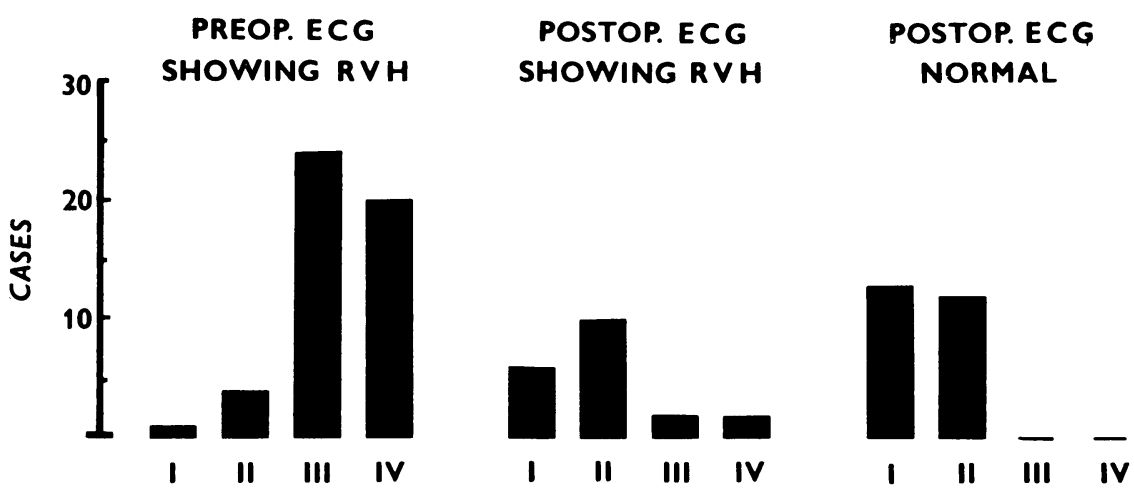

GRADES

FIG. 8.-Functional classification and electrocardiographic pattern before and after operation.

in one patient). There have been no late deaths. There was a close but incomplete correlation between the electrocardiographic change and functional improvement (Fig. 8).

\section{Discussion}

Electrocardiographic evidence of RVH reflects an increased right ventricular mass proportional to the work of the right ventricle (RV). In mitral stenosis pulmonary arterial hypertension is the main cause of the increase in RV work. It seems probable that the increased load is insufficient to give rise to $\mathrm{RV}$ dominance on the cardiogram if the pulmonary vascular resistance (PVR) remains normal (Lancet, 1957). Wood (1954) found a close correlation between cardiographic evidence of RVH and the PVR, but Goodwin et al. (1955) did not find such a close correlation between the cardiogram and the pulmonary pressure: the latter, however, assessed the pulmonary arterial pressure from the radiological appearances, a method of rather doubtful accuracy. We have never 
encountered RVH in patients with a normal PVR and we feel it is reasonable to regard the presence of $\mathrm{RVH}$ on the cardiogram as implying a raised PVR.

Accepting this correlation between RVH and the PVR, it follows that regression of the cardiographic signs after valvotomy implies a fall in PVR. This assumption, however, may not be entirely valid. Donald et al. (1957) found that, after successful valvotomy, there was a striking fall in RV work, but this was only in part due to a fall in PVR and pulmonary arterial pressure although both these parameters were invariably reduced. An important factor was a fall in cardiac output, an unexpected and inexplicable finding. Thus, a pre-operative RV cardiogram certainly means a raised PVR, but post-operative return of the cardiogram to normal although implying a fall in PVR may not necessarily mean a restoration of it to normal.

It is generally accepted that the pulmonary arterial pressure may fall and the cardiographic signs of RVH regress after successful valvotomy. There is some doubt, however, as to the proportion of cases of this kind that will respond to operation in this manner. Mackinnon et al. (1956) noted striking improvement with the ultimate return to normal in 2 of 5 such cases submitted to operation; in a third the period of follow-up was too short to permit assessment. In Mounsey's (1957) series of 100 patients, there were 41 in this group: after operation the cardiographic changes of RVH regressed in only 13 and never returned to normal. Mounsey's experience was quoted by Evans and Short (1957) as an argument against submitting this type of case to operation. Our results are at variance with these, for the cardiogram returned to normal in no less than 59 per cent and improved to some degree in a further 12 pir cent. But there are other, and more cogent reasons for advising operation in this group. Functional improvement is often striking (Fig. 8) and many patients completely disabled before valvotomy now lead a normal life with little or no disability. Here our experience tallies with that of Baker et al. (1955) and Mounsey (1957), both of whom observed that there was little difference in the incidence and extent of functional improvement during the first two to five years after valvotomy in cases with or without pulmonary hypertension, and it must be remembered that these are patients in whom the untreated prognosis is extremely poor.

A good operative split is a prerequisite to success, but although it increases the likelihood of a good result with regression of the cardiographic changes it does not ensure it (Fig. 4). The benefit of increasing surgical experience was excluded by the finding of somewhat better results amongst cases operated on during the first three years compared with those done during the second three years. Age and sex do not appear to be important.

The duration of symptoms prior to operation is important; signs of RVH regressed in 70 per cent of cases operated upon within 7 years of the onset of symptoms compared with only 45 per cent in the over 7-year group (Fig. 7). Presumably this is a reflection of the fact that persistent pulmonary hypertension, whatever the initial genesis may be, causes secondary structural changes: these figures are a strong argument for early operation. In those cases showing regression, the time needed for this to occur varied widely, and the explanation of this is uncertain. We are ignorant of the time required after operation for the maximum drop in PVR to occur, for serial post-operative catheterization studies are few. There is little doubt that at least some weeks may be needed, but the data given by Baker et al. (1955) and Donald et al. (1957) suggests that little further change occurs after approximately six months. The findings in some of our cases suggest a much slower regression of vascular changes but we have already noted that post-operative change in the electrocardiogram may not be an entirely accurate index of the change in PVR. Moreover, the speed with which RVH will regress is affected by the extent as well as the rapidity of the fall in RV work.

\section{CONCLUSIONS}

In 60 patients with mitral stenosis and RV dominance in the electrocardiogram the operative mortality was high $(18 \%)$. In $29(59 \%)$ of the 49 survivors the cardiogram ultimately returned to normal, the time required ranging from under three months to two years. In a further $6(13 \%)$ it improved although showing $\mathrm{RVH}$, while in $14(28 \%)$ there was no change. Change in the 
cardiogram was unrelated to age or sex but occurred much more frequently if the history was short. It may be inferred that a high pulmonary vascular resistance is to a large extent potentially reversible and therefore does not constitute a contra-indication to operation. Indeed, it is in this group that some of our most striking operative successes have been achieved and we are in agreement with Baker, Brock, and Campbell (1955) who remarked "... the greater the degree of pulmonary hypertension the greater the chance of success from valvotomy."

\section{SUMMARY}

Mitral valvotomy has been performed in 60 patients with mitral stenosis and electrocardiographic evidence of RVH. Eleven (18\%) patients died within 24 hours of operation and the remaining 49 have been reviewed with periodic assessment of their clinical state and electrocardiogram. The electrocardiogram returned to normal in $29(59 \%)$, improved in $6(13 \%)$, and was unchanged in $14(28 \%)$.

The significance of these findings has been discussed.

We wish to thank Dr. A. Morgan Jones for his help and for permission to study patients under his care, Mr. R. C. de Meneaud for his technical assistance, and Mrs. K. M. Morgan for secretarial help.

\section{REFERENCES}

Baker, C., Brock, R., and Campbell, M. (1955). Brit. med. J., $2,983$.

Carter, E., Richter, C. P., and Greene, C. H. (1919). Bull. Johns Hopk. Hosp., 30, 162.

Donald, K. W., Bishop, J. M., Wade, O. L., and Wormald, P. N. (1957). Clin. Sci., 16, 325.

Evans, W., and Short, D. S. (1957). Brit. Heart J., 19, 457.

Goodwin, J. F., Hunter, J. D., Cleland, W. P., Davies, L. G., and Steiner, R. E. (1955). Brit. med. J., 2, 573.

Lancet Editorial (1957). The Electrocardiogram in Mitral Valve Disease. Lancet, 1, 1288.

Mackinnon, J., Wade, E. G., and Vickers, C. F. H. (1956). Brit. Heart J., 18, 449.

Milnor, W. R. (1957). Circulation, 16, 348.

Mounsey, P. (1957). Brit. med. J., 2, 311.

Myers, G. B., Klein, H. A., and Stofer, B. E. (1948). Amer. Heart J., 35, 1.

Sokolow, M., and Lyon, T. P. (1949). Amer. Heart J., 38, 273.

Wood, P. (1954). Brit. med. J., 1, 1051. 